\title{
Stratospheric HBr concentration profile obtained from far-infrared emission spectroscopy
}

\author{
I. G. Nolt, ${ }^{1}$ P. A. R. Ade, ${ }^{2}$ F. Alboni, ${ }^{3}$ B. Carli, ${ }^{4}$ M. Carlotti, ${ }^{3}$ U. Cortesi, ${ }^{4}$ M. Epifani, ${ }^{4}$ \\ M. J. Griffin, ${ }^{2}$ P. A. Hamilton, ${ }^{2}$ C. Lee, ${ }^{2}$ G. Lepri, ${ }^{3}$ F. Mencaraglia ${ }^{4}$ A. G. Murray, ${ }^{2}$ \\ J. H. Park, ${ }^{1}$ K. Park, ${ }^{5}$ P. Raspollini, ${ }^{4}$ M. Ridolfi, ${ }^{4}$ and M. D. Vanek ${ }^{1}$
}

\begin{abstract}
Hydrogen bromide $(\mathrm{HBr})$ is the principal bromine sink species for the ozone loss chemistry induced by brominecontaining gases in the stratosphere. We report a 1994 balloon-based measurement of the daytime stratospheric $\mathrm{HBr}$ profile between 20 and $36.5 \mathrm{~km}$ altitude. The average concentration result of $1.31 \pm 0.39$ parts per trillion in volume (pptv) and an analysis for the concentration versus altitude profile are consistent with previously reported measurements. These results strengthen the evidence for a significantly higher $\mathrm{HBr}$ concentration than that predicted by current photochemical models which, on the basis of recent kinetics results, do not include significant $\mathrm{HBr}$ production by the reaction branch, $\mathrm{BrO}+\mathrm{HO}_{2} \rightarrow \mathrm{HBr}+\mathrm{O}_{3}$.
\end{abstract}

\section{Introduction}

A concerted international study is underway to determine whether bromine-containing gases pose a significant threat to the Earth's protective ozone layer. A principal source gas of concern is methyl bromide which is emitted to the atmosphere from a number of natural and anthropogenic sources (Kurylo et al, 1994). While the first exposition of possible bromine catalyzed destruction of ozone was made in 1980 (Yung, et $a l$.$) , research has expanded recently with the recognition that$ regulation of methyl bromide production may be required, in addition to that of CFC, for the protection of the Earth's ozone layer (Kurylo et al, 1994). The phase out of the use of methyl bromide as a major soil fumigant presents a potential impact to agricultural productivity.

The complex nature of upper atmospheric chemistry dictates that measurements be made in the atmosphere itself as a check on the modeling predictions of bromine-related ozone loss processes in the stratosphere. The atmospheric budget of bromine compounds can be categorized into source, reactive, and sink components. A critical determinant of methyl bromide's ozone depletion potential (ODP) is the relative fractions of bromine in the principal reactive and sink forms, i.e. $\mathrm{BrO}$ and $\mathrm{HBr}$, respectively. In situ measurements of $\mathrm{BrO}$ have been reported from a polar balloon flight by Toohey

\footnotetext{
${ }^{1}$ NASA Langley Research Center, Hampton, Virginia.

${ }^{2}$ Queen Mary and Westfield College, London, UK.

'Dipartimento di Chimica-fisica e Inorganica, Universita' di

Bologna, Italy.

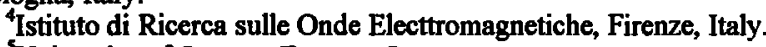

'University of Oregon, Eugene, Oregon.
}

Copyright 1997 by the American Geophysical Union.

Paper number 97GL00034.

0094-8534/97/97GL-00034\$05.00
(1995), and from ER-2 aircraft flights in the ASHOE/MAESA program. Outside the tropics, the aircraft in situ $\mathrm{BrO}$ measurement is combined with other simultaneous measurements to infer that $\mathrm{BrO}$ comprises about $50 \%$ of total inorganic bromine $\mathrm{Br}_{\mathrm{y}}, \mathrm{HOBr}$ about $30 \%$, and $\mathrm{BrONO}_{2}$ about $20 \%$, where $\mathrm{Br}_{\mathrm{y}}=\mathrm{BrO}, \mathrm{BrONO}_{2}, \mathrm{HOBr}, \mathrm{Br}, \mathrm{BrCl}$, and $\mathrm{HBr}$ (Stimpfle et al, 1995).

A relatively inactive form of bromine in the stratosphere is hydrogen bromide ( $\mathrm{HBr}$ ) and, although a small fraction of Bry, uncertainty in its rate of formation has been a significant uncertainty in the calculated bromine ODP (Ko,1993; Kurylo et al, 1994). The following reaction (2)

$$
\begin{aligned}
\mathrm{BrO}+\mathrm{HO}_{2} & \rightarrow \mathrm{HOBr}+\mathrm{O}_{2} \\
& \rightarrow \mathrm{HBr}+\mathrm{O}_{3}
\end{aligned}
$$

has been proposed as a reaction pathway which could increase $\mathrm{HBr}$ and thus serve to reduce the bromine ODP. A recent laboratory measurement of this reaction set yielded an upper limit of $1.5 \%$ for reaction (2) compared to reaction (1) at stratospheric temperatures (Larichev et al, 1995), while an earlier indirect measurement using the reverse of reaction (2) resulted in a much smaller branching limit of $<0.01 \%$ (Mellouki et al , 1994).

An early workshop on methyl bromide in 1992 identified significant differences between model estimates of stratospheric $\mathrm{HBr}$ and the limited experimental data then available (Park et al 1989; Traub et al, 1992). As a result efforts were undertaken to improve the sensitivity for measuring the $\mathrm{HBr}$ content of the stratosphere. By 1995 the experimental measurements by two research groups were consistent in showing an average stratospheric $\mathrm{HBr}$ concentration of less than two pptv (Johinson, et al, 1995, Carlotti et al, 1995). This paper compares our 1994 flight results to these previously reported measurements.

The $\mathrm{HBr}$ molecule is well suited for detection by far infrared emission spectroscopy as it has a relatively large dipole moment which produces a strong emission intensity on a per molecule basis. Furthermore, as a consequence of having a nearly equal abundance of two bromine isotopes $\left({ }^{79} \mathrm{Br}\right.$ and ${ }^{81} \mathrm{Br}$ ), its rotational line emission consists of closely spaced doublets which adds confidence to the $\mathrm{HBr}$ spectroscopic assignment. Instrument sensitivities were improved with development of narrowband photon-noise-limited photoconductive detectors (NB-PC)(Murray et al., 1992). The first NB-PC system was incorporated in our Infrared Balloon Experiment (IBEX) flight of May 4, 1993, for detection of the $\mathrm{HBr}$ $(\mathrm{J}=2 \leftarrow 3)$ transition doublet near $50 \mathrm{~cm}^{-1}$ (200 $\mu \mathrm{m}$ wavelength). The essential result of the 1993 flight was a measured $\mathrm{HBr}$ concentration of $1.6 \pm 0.6$ parts per trillion (pptv) between 25 and $36.5 \mathrm{~km}$ altitude (Carlotti et al, 1995]. For 

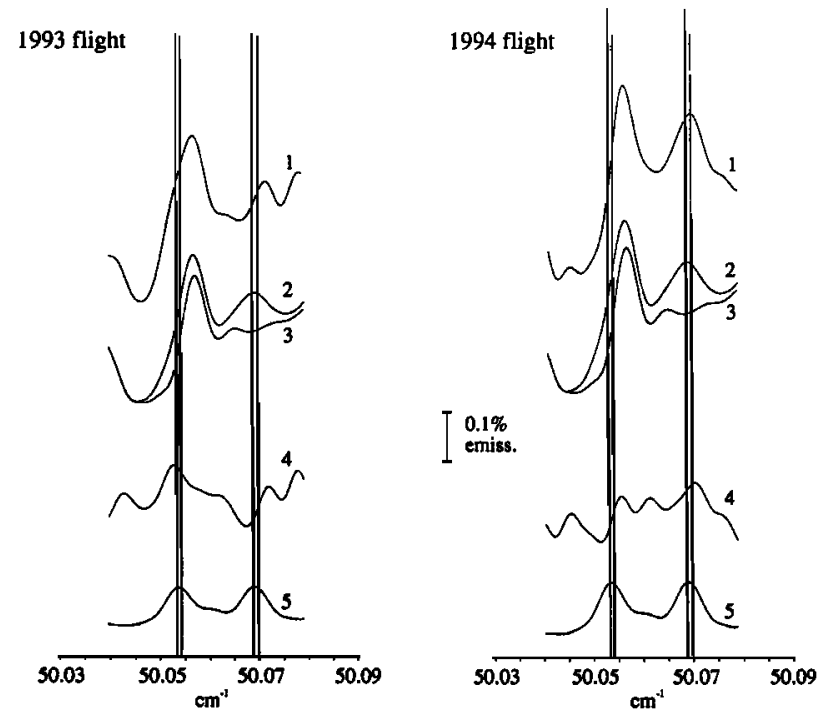

Figure 1. This figure compares the global fitting results for the 1993 and 1994 balloon flights for similar altitude and daytime conditions. This is a highly expanded display of the average emission spectrum of the $\mathrm{HBr}$ region, where curve 1 shows the average of 117 spectra obtained in 1993 (Case E of Table 1) and 108 spectra in 1994 (Case A), for the altitude range from 20 to $36 \mathrm{~km}$. Curve 2 is the average of the simulated spectra after convergence by the global fitting algorithm, and curve 4 is the residual difference between curves 1 and 2 . Curve 3 is the average of the simulated spectra as in curve 2 but with no $\mathrm{HBr}$ included in the simulations, so that curve 5 , which is the difference between curve 2 and curve 3 , represents the spectral component attributed to $\mathrm{HBr}$ emission of the two equally abundant isotopes, $\mathrm{H}^{79} \mathrm{Br}$ and $\mathrm{H}^{81} \mathrm{Br}$. The apodized instrumental resolution of $0.0035 \mathrm{~cm}^{-1}$ resolves the isotopic transitions where the lower frequency line shows interference by an isotopically substituted ozone transition. The vertical lines show the known frequencies and the hyperfine splitting of the $\mathrm{J}=2 \leftarrow 3$ rotational transition.

the 1994 campaign, the same detection system was flown with excellent system and balloon altitude performance.

\section{Measurements}

The results reported here were obtained in a 1994 balloon flight campaign which was part of an international cooperative effort in support of correlative measurements for the Upper Atmosphere Research Satellite. The flight instrument combines a high resolution Fourier transform emission spectrometer developed in Italy (Carli et al. 1984), with advanced detector technology from the UK (Murray et al., 1992). The data presented here were obtained May 14/15, 1994 on a balloon payload launched from Fort Sumner, NM, (34.5 deg N, $104 \mathrm{~W}$ ). The flight maintained a float altitude of $36 \pm 1.5 \mathrm{~km}$ for a full $20 \mathrm{hrs}$ of measurement, about equally divided between day and night.

The experimental data were obtained in the following fashion. From the balloon float altitude of $36 \mathrm{~km}$, the optical instrument viewed the limb emission of the atmosphere at a sequence of elevation angles, with a typical tangent height increment of $1.5 \mathrm{~km}$. At each elevation angle, the interferometer
Table 1. Mixing ratio of stratospheric $\mathrm{HBr}$

\begin{tabular}{cccccc}
\hline Case & $\begin{array}{c}\text { Altitude }^{(1)} \\
(\mathrm{km})\end{array}$ & $\begin{array}{l}\text { Flight } \\
(\mathrm{m} / \mathrm{d} / \mathrm{y})\end{array}$ & $\begin{array}{c}\text { No. } \\
\text { Scans }\end{array}$ & $\begin{array}{c}\text { M. R. }^{(2)} \\
\left(10^{-12}\right)\end{array}$ & Ref \\
\cline { 1 - 6 } & 20 to 36.5 & $5 / 14 / 94$ & 108 & $1.31(39)$ & $(3)$ \\
B & 34.6 & $5 / 14 / 94$ & 108 & $1.78(1.42)$ & $(3)$ \\
& 28.0 & & & $2.43(97)$ & \\
& 21.2 & & & $0.85(68)$ & \\
C & 22 to 34 & $1988-94$ & 7 flights & $2.00(80)$ & $(4)$ \\
D & 25 to 36.5 & $5 / 31 / 93$ & 121 & $1.60(60)$ & $(5)$ \\
E & 20 to 36.5 & $5 / 31 / 93$ & 117 & $1.15(46)$ & $(6)$ \\
\hline
\end{tabular}

(1) A uniform mixing ratio is assumed when a range is specified for the altitude.

(2) The uncertainties in the right-most digits of mixing ratios (in parentheses) are the quadrature sum of the 1- $\sigma$ random errors (precision) from the global fit to unapodized data (Cases A, D, \& E) and an estimated $15 \%$ systematic error. See Carlotti et al (1995) for a discussion of the systematic errors.

(3) This paper.

(4) Johnson et al, 1995.

(5) Carlotti et al, 1995.

(6) Modified Carlotti et al, 1995.

moving mirror scanned an optical path difference of $2 \mathrm{~m}$ in a time of $2.7 \mathrm{~min}$, providing an unapodized spectral resolution of $0.0025 \mathrm{~cm}^{-1}$. Periodically a black-body reference source replaced the limb beam for calibration and normalization of the limb spectra. The spectral bandwidth of the channel is defined by a cryogenically-cooled filter, which served to limit the photon flux, and hence fundamental photon noise, incident upon the stressed Ge:Ga photodetector. The spectral channel for this measurement was centered at $50 \mathrm{~cm}^{-1}$, with a bandwith (FWHM) of about $2 \mathrm{~cm}^{-1}$. During the scan, the output signal comprising the interferogram is digitized and relayed by telemetry to the ground for recording. Each digitized interferogram had a nominal 158,000 points. Subsequently, Fourier transform spectra were computed and normalized relative to the black-body reference spectra. Additional details of the instrument can be found in Carlotti et al, (1995).

\section{Results}

Our objectives were to extend our analysis using the same retrieval procedures as for the ' 93 flight data (Carlotti, 1988 \& Carlotti et al., 1995) and, in view of the better 1994 balloon and instrument performance, to evaluate the altitude dependence for $\mathrm{HBr}$. All the retrieval analyses reported here were carried out at the University of Bologna and use the global-fit analysis described in Carlotti, et al (1995). Briefly in this procedure all the spectra are fit simultaneously but each with a synthetic spectrum calculated with the corresponding observing geometry. The ozone profiles, which are needed to model nearby features, were separately determined and treated as known inputs in the $\mathrm{HBr}$ fitting. The relatively weak water vapor features were adequately fit with a standard profile. Finally, a non-linear least squares fit was used to determine the $\mathrm{HBr}$ mixing ratio. The atmospheric line database used for modeling the simulated spectrum was the 1992 release of 


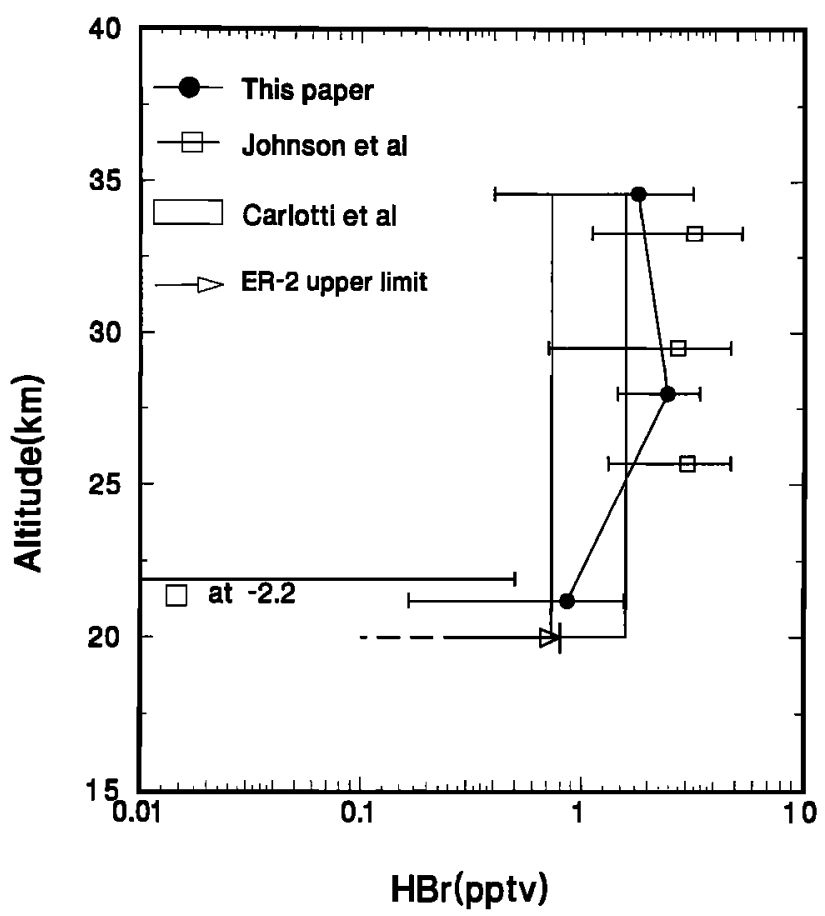

Figure 2. This figure compares the daytime mixing ratio profiles of $\mathrm{HBr}$ obtained in our 1993 and 1994 balloon flights, and the profile by Johnson et al (1995). The errors are the one-sigma estimate of the total uncertainty which in our cases includes the fitting error (precision) obtained for the global fit as described in the text, added in quadrature to an estimated systematic error of $15 \%$. The retrieval for the 1993 measurement (case $E$ in Table 1) assumed uniform mixing over the indicated altitude range. The upper limit estimate at $20 \mathrm{~km}$ altitude is inferred from in situ aircraft measurements as described in the text (Stimpfle, private communication, 1996).

HITRAN (Rothman et al, 1992) supplemented by the JPL catalog (Poynter and Pickett, 1985), and SAO database (Chance et al, 1994). The $\mathrm{HBr}$ frequencies are known to high accuracy (Di Lonardo et al, 1991).

Figure 1 compares the observed and simulated emission features of $\mathrm{HBr}$ for the 1993 and 1994 flights. These averages of apodized spectra on a highly expanded scale illustrate the $\mathrm{HBr}$ emission component relative to the residual of the fit. The spectral averages compared for the two flights in this figure encompass the same altitude range and are for daytime observations. In addition, the simulation uses an improved model for the instrument lineshape compared to that used in the Carlotti et al (1995) reference. The reproducibility of the two flights is quite good with a slightly smaller residual for the 1994 data.

In Table 1, we compare the 1994 flight results (Case A) to previously published results (Cases C \& D). We also show the '93 data re-analyzed (Case E) to match the conditions of the ' 94 result (Case A).

In an attempt to extract information for the altitude dependence of the $\mathrm{HBr}$ mixing profile, we made retrievals relaxing the constraint of a uniform mixing ratio. Using unapodized spectra we had difficulty obtaining a statistically meaningful result, probably due to inperfect modeling of the large "ringing" features interfering with the very weak $\mathrm{HBr}$ emissions. Using linearly apodized spectra for the retrieval reduced the spurious interfering sidelobes or "ringing" from

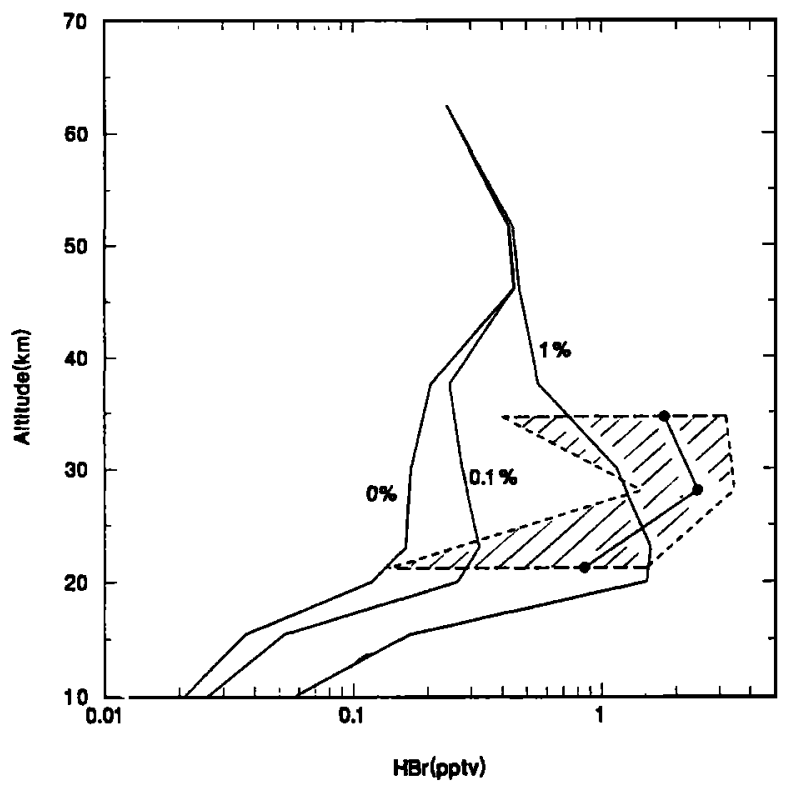

Figure 3. This figure compares the experimental measurement of $\mathrm{HBr}$ concentration to the calculated mid-latitude concentrations for local noon using a gas phase model as given in Lary (1996). The model results are shown for three values of the branching ratio for the yield of $\mathrm{HBr}$ in the reaction of $\mathrm{BrO}$ with $\mathrm{HO}_{2}$ to produce either $\mathrm{HOBr}$ or $\mathrm{HBr}$. The experimental data is case $B$ in Table 1 .

nearby lines, and resulted in good convergence of a fit for a three-point profile between 25 and $35 \mathrm{~km}$ altitude. However, apodization introduces correlation between adjacent spectral values, and the global-fit error estimate, which assumes linearly independent spectral values, is not correctly estimated in this case. To account for this correlation effect we have increased by $70 \%$ the errors estimated by the global fit using apodized data. The result is Case B in Table 1. In Figure 2 this result is compared to the 1993 average daytime concentration result (case E in Table 1), to the Johnson et al (1995) profile (obtained from $\mathrm{HBr}$ rotational lines at 99.9 and 116.4 $\mathrm{cm}^{-1}$ ), and to an upper limit for $\mathrm{HBr}$ at $20 \mathrm{~km}$ inferred from aircraft measurements. This latter model-based $\mathrm{HBr}$ upper limit is about $4 \%(0.8 \mathrm{pptv})$ of the total inorganic bromine $\left(\mathrm{Br}_{\mathrm{y}}\right)$ and is estimated from a $\mathrm{BrO}$ plus other in-situ measurements in the 1994 ASHOE campaign (Stimpfle, private communication, 1996).

\section{Discussion}

An important test of our understanding of bromine chemistry and its ozone depletion potential is the comparison of active and reservoir concentrations in the stratosphere to model predictions. The recent study of the conversion of $\mathrm{BrO}$ to $\mathrm{HBr}$ by the reaction of $\mathrm{BrO}$ with $\mathrm{HO}_{2}$ (Larichev et al, 1995) yielded an upper limit of $1.5 \%$ for the reaction branch for $\mathrm{HBr}$ (see eq. 2), but a study of the reverse reaction gave a branching ratio of less than 0.01\% (Mellouki et al, 1994). In Figure 3 we compare the measured $\mathrm{HBr}$ concentration to model calculations for different values of this branching ratio. The model results are those calculated by Lary (1996) for mid-latitude, local noon using the 3-d transport model of Cambridge University. Similar results were also reported at an earlier workshop on methyl bromide (Ko, 1993). The model comparisons to the 
experimental results constrain the reaction for the production of $\mathrm{HBr}$ by reaction (2) to have a branching ratio between one and two per-cent, taking into account the uncertainty in inorganic bromine ( $\approx \pm 15 \%$, Fish et al, 1995). 'Alternately, in view of the kinetics evidence against a branching ratio of this magnitude, some other significant pathway may exist for the production of $\mathrm{HBr}$ in the mid-stratosphere or the $\mathrm{HBr}$ loss rate may be less than modeled. In any case, the effective sequestration of about $5 \%$ of total inorganic bromine as $\mathrm{HBr}$ implies about a $10 \%$ reduction in ODP compared to a model which assumes negligible $\mathrm{HBr}$ formation by reaction (2) (Ko 1993).

Acknowledgments. We gratefully acknowledge the support of this work by the Methyl Bromide Global Coalition. In addition, other support was provided by the Correlative Measurements Program of the Upper Atmosphere Research Program Office, and NASA Grant NAG1-963 to the University of Oregon. In Italy support was provided by the Consiglio Nazionale delle Ricerche, and the Italian Space Agency (ASI). In the UK, support was provided by the Natural Environment Research Council grant GR/154987. Excellent flight launch and system support was furnished by the Balloon Support Group of the Jet Propulsion Laboratory, and the National Scientific Balloon Facility, both of which operate under contract to NASA.

\section{References}

Carli, B., F. Mencaraglia, and A. Bonetti, Sub-millimeter High Resolution Fourier Transform Spectrometer for Atmospheric Studies, Appl. Opt., 23, 2594-2603, 1984.

Carlotti, M., Global-fit Approach to the Analysis of limb-scanning Atmospheric Measurements, Appl. Opt., 27, 3205-3254, 1988.

Carlotti, M., P. A. R. Ade, B. Carli, P. Ciapallini, U. Cortesi, M. J. Griffin, G. Lepri, F. Mencaraglia, A. G. Murray, I. G. Nolt, J.H. Park, and J. V. Radostitz, Measurement of Stratospheric $\mathrm{HBr}$ using High Resolution Far Infrared Spectroscopy, Geophys. Res. Lett., 22, 3207-3210, 1995.

Chance, K. V., K. W. Jucks, D. G. Johnson, and W. A. Traub, The Smithsonian Astrophysical Observatory Database SAO92, J. Quant. Spectrosc. Radiat. Transfer, 52, 445-457, 1994.

Di Lonardo G., L. Fusina. P. De Natale, M. Inguscio and M. Prevedelli, The Pure Rotation Spectrum of $\mathrm{HBr}$ in the Submm Region, J. Mol. Spectrosc., 148, 86-92, 1991.

Fish, D. J., R. L. Jones and E. K. Strong, Midlatitude Observations of the diurnal variation of Stratospheric BrO, J. Geophys. Res. $100,18,863-18,871,1995$

Johnson, D. G., W. A. Traub, K. V. Chance, and K.W. Jucks, Detection of $\mathrm{HBr}$ and Upper Limit for HOBr: Bromine Partitioning in the Stratosphere, Geophys. Res. Lett., 22, 1373-1376, 1995.

Ko, M. K. W, Ozone Depletion Potential of Methyl Bromide, Sensitivity to Uncertainties in Rate Data, Second Methyl Bromide State of Science Workshop, Washington D.C., Oct. 28 , 1993.
Kurylo, M. J., J. A. Kaye, R. F. Hampson, and A. M. Schmoltner, Present State of Knowledge of the Upper Atmosphere 1993: An Assessment Report, NASA Ref. Publ. 1337,p. 24, January 1994.

Larichev, M, F. Maguin, G. Le Bras, and G. Poulet, Kinetics and Mechanism of $\mathrm{BrO}+\mathrm{HO}_{2}$ Reaction, J. Phys. Chem., 99, 15911-15918, 1995.

Lary, D. J., Gas Phase Atmospheric Bromine Chemistry, J. Geophys. Res., 101-D1, 1505-1516, 1996.

Mellouki, A., R. K. Talukdar, and C. J. Howard, Kinetics of the Reactions of $\mathrm{HBr}$ with $\mathrm{O}_{3}$ and $\mathrm{HO}_{2}$ : The Yield of $\mathrm{HBr}$ from $\mathrm{HO}_{2}$ + BrO, J. Geophys. Res., 99(DI1), 22,949-22,954, 1994.

Murray, A. G., M. J. Griffin, P. A. R. Ade, J. Leotin, C. Meny, and G. Sirmain, Optimisation of FIR Photoconductors for Atmospheric Spectroscopy, Paper presented at ESA Symposium on Photon Detectors for Space Instrumentation, Noordwijk, 10-12 Nov, 1992, ESA SP-356, 1992.

Park, J. H., B. Carli, and A. Barbis, Stratospheric HBr Mixing Ratio from Far Infrared Emission Spectroscopy, Geophys. Res. Lett., 16, 2305-2308, 1989.

Poynter, R. L., and H. M. Pickett, Submillimeter, Millimeter, and Microwave Spectral Line Catalog, Appl. Opt., 24, 2235-2240, 1985.

Rothman, L. S., R. R. Gamache, A. Goldman, L. R. Brown, R. A. Toth, H. M. Pickett, R. L. Poynter, J-M Flaud, C. Camy-Peyret, A. Barbe, N. Husson, C. P. Rinsland, and M. A. H. Smith, The HITRAN Database: 1986 Edition, Appl. Opt., 26, 4058-4097, 1986.

Stimpfle, R. M., W. Kohn, P. O. Wennberg, R. C. Cohen, and J. G. Anderson, BrO Measurements from the ASHOE/MAESA Mission, Third Methyl Bromide State of Science Workshop, June 57, 1995, Monterey, CA.

Toohey D. W., Development of a Balloon-borne System for In Situ Measurements of BrO, Third Methyl Bromide State of Science Workshop, June 5-7, 1995, Monterey, CA.

Traub, W. A., D. G. Johnson, K. W. Jucks, and K. V. Chance, Upper Limit for Stratospheric $\mathrm{HBr}$ using Far-infrared Thermal Emission Spectroscopy, Geophys. Res. Lett., 19, 1651-1654, 1992.

Yung, Y. L., J. P. Pinto, R. T. Watson and S. P. Sander, Atmospheric Bromine and Ozone Perturbations in the Lower Stratosphere, J. Atm. Sci., 37, 339-353, 1980.

I. G. Nolt, J. H. Park, and M. D. Vanek, NASA Langley, Hampton, VA.

P. A. R. Ade, M. J. Griffin, P. A. Hamilton, C. Lee, and A. G. Murray, Queen Mary and Westfield College, London, UK.

B. Carli, U. Cortesi, M. Epifani, F. Mencaraglia, P. Raspollini, and M. Ridolfi, IROE, Firenze, Italy.

F. Alboni, M. Carlotti and G. Lepri, University of Bologna, Italy.

K. Park, University of Oregon, Eugene, $O R$.

(Received October 7, 1996; revised December 23, 1996; accepted December 30, 1996) 